\title{
The Hospital Pharmacist: An Important Contributor to Improved Patient Safety in the Hospital
}

\author{
Stéphanie Berthouzoz ${ }^{\mathrm{ab}}$, Lina Berger ${ }^{\mathrm{a}}$, Pascal Bonnabry ${ }^{\mathrm{bc}}$, and André Pannatier ${ }^{\mathrm{ab}}$
}

\begin{abstract}
Injectable drugs are high-risk products and their reconstitution in hospital wards is a potential source of errors. Thus, in order to secure the reconstitution process and thereby improve safety, the pharmacy department of Lausanne University Hospital is focusing on developing ready-to-use forms (CIVAS). These preparations are compounded in controlled clean rooms and are analyzed prior to release. In the intensive care unit, amiodarone $12.5 \mathrm{mg} / \mathrm{mL}$ in glucose $5 \%$ is one of the high-risk preparations, which has led the pharmacy to develop a ready-to-use solution. To this end, a one-year stability study was initiated, and the preliminary results (after six months) are illustrated here. A stability-indicating HPLC method was developed and validated for monitoring the concentration of amiodarone. Batches were stored at $5{ }^{\circ} \mathrm{C}$ and $30^{\circ} \mathrm{C}$, which were analyzed immediately after preparation, after one, two, four and six months of storage. The $\mathrm{pH}$ and osmolality values were monitored at the respective time intervals. It was observed that after six months, all the results were within specifications. However, the $\mathrm{pH}$ values started to decrease after two months when amiodarone was stored at $30^{\circ} \mathrm{C}$. After six months, a degradation peak appeared on the chromatogram of these solutions, which suggested that amiodarone is more stable at $5{ }^{\circ} \mathrm{C}$. The preliminary results obtained in this study indicated that injectable amiodarone solutions are stable for six months under refrigerated storage conditions. The study is ongoing.
\end{abstract}

Keywords: Amiodarone · CIVAS · Ready-to-use · Injectable · Stability

\section{Medication Safety}

Since the publication of the report 'To err is human, building a safer health system' by the Institute of Medicine in 1999, [1] considerable efforts have been undertaken to improve the safety of medication care in hospitals. It was estimated that the number of deaths attributable to preventable medical errors was between 44,000 and 98,000 per year in the USA and that 7,000 Americans could die annually from medication errors alone.

Observation studies evaluated the distribution of medication errors in the various steps of the process. Based on these studies it was concluded that human factors have a major influence and that the higher risks of error are related to the prescription and administration of drugs. The ability to intercept errors before they

${ }^{*}$ Correspondence: Prof. A. Pannatierab

Tel.: +41795563230

Fax: +4121314 4992

E-mail: Andre.Pannatier@chuv.ch

aDepartment of Pharmacy, University Hospital

Lausanne University Hospital

Rue du Bugnon 46, $\mathrm{CH}-1011$ Lausanne

'School of Pharmaceutical Sciences

University of Geneva, University of Lausanne

Quai Ernest-Ansermet 30, CH-1211 Geneva 4

'Department of Pharmacy, University Hospitals

Rue Gabrielle-Perret-Gentil 4, CH-1211 Geneva 14 affected patients was found to be lower for the administration step ( $2 \%$ vs. $50 \%$ for prescription errors).

Thus, to improve medication safety, interdisciplinary actions with a strong involvement of hospital pharmacists was developed in three main fields of action (the 3 'Ps'):

- Improve the process reliability by redesigning the organization and implementing information technologies;

- Improve the persons' (healthcare professionals, patients) performance by educative actions, i.e. through clinical pharmacy activities;

- Improve the product ergonomics, by reducing high-risk steps (e.g. dilutions) and optimizing the available information (e.g. packaging, leaflets).

\section{Ready-to-use Injectable Drugs (CIVAS)}

Injectable drugs are high-risk products and their reconstitution in wards is a source of errors, particularly when the dilution is complex and is performed under stress. Thus, to improve their safety, it is recommended to provide these drugs in ready-touse forms. Hospital pharmacists motivate the pharmaceutical industry to develop such products and implement in-house facilities that would enable them to produce the more risky preparations (Centralized IntraVenous Additive Services, CIVAS). Historically, parenteral nutrition and cytostatic medicines were the first drugs to be provided as ready-to-use by the hospital pharmacy. ${ }^{[2]}$ More recently, other injectable drugs such as those mainly used in intensive care, anesthesiology, emergency, pediatrics, and ophthalmology have also been proposed.[3]

To ensure optimal safety, the production of CIVAS must rely on a very high quality assurance system, and should be performed in accordance with Good Manufacturing Practices (GMPs), including controlled clean rooms with laminar airflows or isolators, qualified operators, extensive documentation (SOPs, protocols), full traceability, and quality controls involving validated methods.

The development of new products necessitates stability studies to demonstrate the feasibility of batch production for the stock. Further, stability-indicating separation methods need to be developed and validated to support the stability study. To achieve this objective, the availability of a high-level pharmaceutical analysis structure is essential.

In conclusion, the procurement of ready-to-use injectable drugs contributes to the improvement of drug use safety in hospitals; however, their development and production is labor-intensive. To opti- 
mize efforts, the priorities of development should be carefully discussed with the endusers.

This research article illustrates an example of CIVAS development.

\section{Development of Ready-to-use Vials of Amiodarone $12.5 \mathrm{mg} / \mathrm{mL}$ in Glucose 5\%: Preliminary Results}

\section{Introduction}

As the patient health status is unstable in intensive care units (ICU), most drugs are administered by the intravenous route. Most injectable medicines are reconstituted prior to administration by the nursing staff. In this context, there is significant workload on the nurses that can be stressful, which implies that reconstitution is a potential source of errors (wrong medicine, wrong concentration, microbiological and particle contamination). The standardization and centralization of preparations and reconstitution by the hospital pharmacy could help reduce the risk probability of these errors.

Amiodarone is a class III antiarrhythmic agent, which is recommended as one of the most powerful drugs used in the treatment of ventricular arrhythmias and atrial fibrillation. ${ }^{[4]}$ Intravenous amiodarone infusion (A-IV) is often performed in emergency situations and its preparation at the bedside by nurses in the ICU presents a high risk of errors and delays. To solve this problem, it is assumed that prior preparation of infusions in a clean pharmaceutical environment would decrease the risk of errors.

Following the request of the ICU staff for ready-to-use A-IV solutions, a reliable protocol was developed to obtain A-IV solutions showing excellent physicochemical and microbiological stabilities. To this end, a one-year stability study was initiated for which the preliminary results after six months are illustrated here.

\section{Material and Methods}

\subsection{Formulation Composition}

Amiodarone $\mathrm{HCl}$ (Saurav Chemicals, Panchkula, India): $600 \mathrm{mg}$; Tween $80 \mathrm{Ph}$ Eur (Hänseler, Herisau, Switzerland): $1200 \mathrm{mg}$; glucose Ph Eur (Hänseler): 2.4 g; water for injection $\left(\right.$ Bichsel $^{\circledR}$, Interlaken, Switzerland): ad $48 \mathrm{ml}$.

\subsection{Preliminary Tests}

A-IV solutions were prepared under different conditions and their stability was examined after one month. As amiodarone is sensitive to oxygen, different nitrogen bubbling times were tested $(30 \mathrm{~min}$ and 60 min). As amiodarone has the potential to precipitate at a temperature below $20^{\circ} \mathrm{C}$ (see Section 3.1), stabilization conditions were tested $\left(60^{\circ} \mathrm{C}\right.$ for $15 \mathrm{~min}$ and $70^{\circ} \mathrm{C}$ for 1h).

\subsection{Preparation of Vials for Stability Studies}

Subsequent to these preliminary tests, the following procedure was chosen for long-term stability studies: sterile water was brought to boiling point and nitrogen bubbling through the solution for $30 \mathrm{~min}$. Amiodarone, Tween 80 and glucose were then added and the suspension was heated in an ultrasonic bath until dissolution. This solution was filtered $(0.22 \mu \mathrm{m})$ and transferred in glass vials (type I, white glass) pre-filled with nitrogen.

A total of six different batches of 35 vials were prepared. Among these, three batches were heated at $60{ }^{\circ} \mathrm{C}$ for $15 \mathrm{~min}$. The vials were stored in the dark at $5{ }^{\circ} \mathrm{C}$ $\pm 3{ }^{\circ} \mathrm{C}$ and at $30{ }^{\circ} \mathrm{C}$ with $65 \%$ humidity. Samples were taken immediately after the preparation of vials (day 0) and after 1, 2, 4 and 6 months for analysis with a stability-indicating high-performance liquid chromatography (HPLC) assay in order to determine amiodarone concentrations. In addition, the $\mathrm{pH}$ and osmolality values of each solution were also measured at each time-point. Further, the samples were also visually inspected against a light background with a matt black part and a non-dazzling white part to check for clarity, color, and the presence of crystalline particulate matter. Stability was defined as retention of at least $90 \%$ of the initial drug concentration.

\subsection{HPLC Analysis}

The HPLC method employed was adapted from an existing method that was originally developed by the pharmacy of Geneva University Hospital.

The HPLC system was composed of a Varian 9012 pump (Walnut Creek, USA), a DAD detector (Varian), and a Varian ProStar 410 injector. Separation was carried out on a Chromolith Performance ${ }^{\circledR}$ RP-18e (100-4.6 mm) column with a Chromolith ${ }^{\circledR}$ $\mathrm{RP}-18 \mathrm{e}$ precolumn. The mobile phase was composed of 50:50 acetonitrile (Merck)/ aqueous buffer $\left(\mathrm{KH}_{2} \mathrm{PO}_{4} 26.5 \mathrm{mM}+0.4 \%\right.$ triethylamine $\mathrm{pH}=2.5)$. The flow rate was $1.5 \mathrm{ml} / \mathrm{min}$ and the temperature was $55^{\circ} \mathrm{C}$. The detection was monitored at $240 \mathrm{~nm}$.

\subsection{Validation of the HPLC Method}

The accuracy profile methodology was used for validating the HPLC method. This methodology is based on the concept of total measurement error (guidelines of the Société Française des Sciences et TechniquesPharmaceutiques(SFSTP)). ${ }^{[5-8]}$
The accuracy profile used only one statistical decision tool, namely, the $\beta$-expectation tolerance interval computed at each concentration level of the validation standards. ${ }^{[7-10]}$

\subsection{Standard Solutions}

A stock solution of amiodarone was prepared by accurately weighing $125.0 \mathrm{mg}$ amiodarone and $250.0 \mathrm{mg}$ Tween 80 and dissolving them in $10.0 \mathrm{~mL}$ glucose $5 \%$ (B. Braun Medical, Sempach, Switzerland). The suspension was heated at $60{ }^{\circ} \mathrm{C}$ until dissolution. The calibration standards for amiodarone were prepared by diluting the stock solution after return to room temperature with the buffer to achieve three concentration levels ranging from 0.05 to $0.075 \mathrm{mg} / \mathrm{mL}$. The validation standards were also prepared in a similar manner. Calibration standards were prepared in duplicate while validation standards were prepared in triplicate. The results were analyzed using the Enoval program (Arlanda, Liège, Belgium).

\subsection{Stability-indicating Method}

To ensure that the degradation products did not interfere, amiodarone was degraded in four different ways: acidic degradation $(\mathrm{HCl} 5 \mathrm{~N})$, basic degradation $(\mathrm{NaOH} 5 \mathrm{~N})$, heat degradation $\left(100{ }^{\circ} \mathrm{C}\right.$ during $\left.24 \mathrm{~h}\right)$, and UV degradation (350 $\mathrm{nm}$ during $24 \mathrm{~h}$ ). The absence of impurities eluting under the amiodarone peak was confirmed by running amiodarone with known impurities (impurity D and E, council of Europe). The purity of the amiodarone peak was verified and the between-peak resolution was measured.

\section{8 $p H$ Determination}

The $\mathrm{pH}$ value of the solution was followed during the entire study. The measurements were made with a Sevenmulti $\mathrm{pH}$-meter (Mettler Toledo, Greifensee, Switzerland).

\subsection{Osmolality Determination}

The osmolality value was measured at each time interval with a Model 3D3 osmometer (Advanced Instrument, Norwood, USA).

\section{Results and discussion}

\subsection{Preliminary Study}

It was found that all of the formulations examined in the preliminary study were stable after a month. As the nitrogen bubbling time did not influence the results, a $30 \mathrm{~min}$ period was found to be sufficient. Although no difference was observed during the first month, it was decided to monitor the effect of heat stabilization for a period of one year because, according to the 


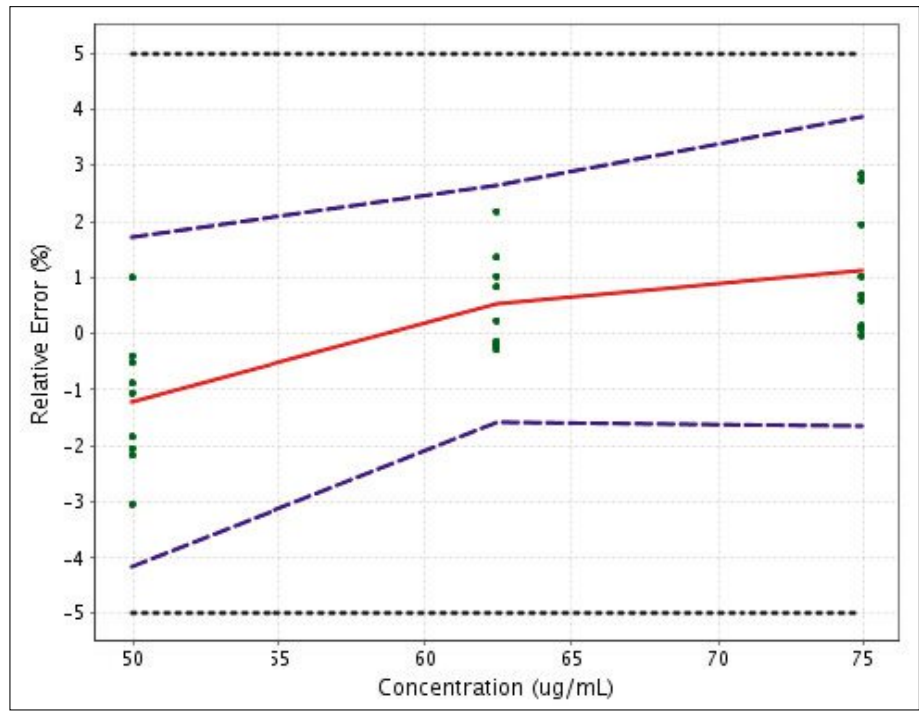

Fig. 1. Accuracy profile obtained for the determination of amiodarone using linear regression forced through the origin using the highest concentration level.
Table 1. Validation results of the method for the determination of $12.5 \mathrm{mg} / \mathrm{mL}$ of amiodarone in glucose $5 \%$

Linear regression forced through the origin using the highest concentration level

Reponses functions

\begin{tabular}{|c|c|c|c|}
\hline & Slope & Intercept & $\mathbf{R}^{2}$ \\
\hline Day 1 & $3.4611 \times 10^{5}$ & na & na \\
\hline Day 2 & $3.5513 \times 10^{5}$ & na & na \\
\hline Day 3 & $3.4253 \times 10^{5}$ & na & na \\
\hline \multicolumn{4}{|c|}{ Accuracy profile approach } \\
\hline entration & $0.05 \mathrm{mg} / \mathrm{mL}$ & $\begin{array}{c}0.0625 \mathrm{mg} / \\
\mathrm{mL}\end{array}$ & $\begin{array}{c}0.075 \mathrm{mg} \\
\mathrm{mL}\end{array}$ \\
\hline $\begin{array}{l}\text { Accuracy } \\
\beta \text {-expectation } \\
\text { ance interval }\end{array}$ & $\begin{array}{c}{[-4.152,} \\
1.726]\end{array}$ & $\begin{array}{c}{[-1.590} \\
2.655]\end{array}$ & $\begin{array}{c}{[-1.636} \\
3.863]\end{array}$ \\
\hline
\end{tabular}

[\%])

Results of linearity

\begin{tabular}{c|c}
\hline Slope & 1.058 \\
\hline Intercept & -3.415 \\
\hline Range & $49.96-74.97 \mu \mathrm{g} / \mathrm{mL}$ \\
\hline $\mathrm{r}^{2}$ & 0.9964 \\
\hline LOQ & $49.96 \mu \mathrm{g} / \mathrm{mL}$ \\
\hline LOD & $1.137 \mu \mathrm{g} / \mathrm{mL}$ \\
\hline
\end{tabular}

manufacturer, amiodarone has a potential to precipitate if the temperature is below $20{ }^{\circ} \mathrm{C}$.

\subsection{HPLC Method}

To apply the accuracy profile methodology, the results were analyzed with the Enoval program (version 3). The results indicate (Fig. 1) that the best calibration function that can be used for dosing is the linear regression model forced through the origin and including the highest concentration level $(0.075 \mathrm{mg} / \mathrm{mL})$.

As indicated by this figure, the calibration model is acceptable as the accuracy profile is fully included into the acceptance limits at $\pm 5 \%$ for all concentrations of the validation standards. All validation results obtained by the chosen calibration model are reported in Table 1.

The stability assays indicated that no degradation product and no impurity interfered with the dosage of amiodarone (Fig. 2 and 3 ).

\subsection{Long-term Study}

After six months, the results (average of the three batches) for stability, $\mathrm{pH}$, osmolality, and visual inspection were all found to be within the acceptance criteria for all concentrations and all types of storage. The results for concentration and osmolality were below $\pm 10 \%$ of the initial one while the $\mathrm{pH}$ ranged between 3.5 and 4.5 (Fig. 4).

These first results indicate that the amiodarone solution was stable for at least six months. However it was observed that after two months, the $\mathrm{pH}$ of the batches at $30{ }^{\circ} \mathrm{C}$ had decreased and a degradation peak appeared in the HPLC traces after four months (Fig. 5).

Nevertheless, the batches stored at $5{ }^{\circ} \mathrm{C}$ showed stable values of $\mathrm{pH}$ and osmolality. Their concentration was found to be $101 \%$ of the initial one after six months and no degradation peak was observed. No difference was found for the batches prepared with or without stabilization. The study is continuing for at least six additional months.

\section{Conclusion}

The concentration used in these assays

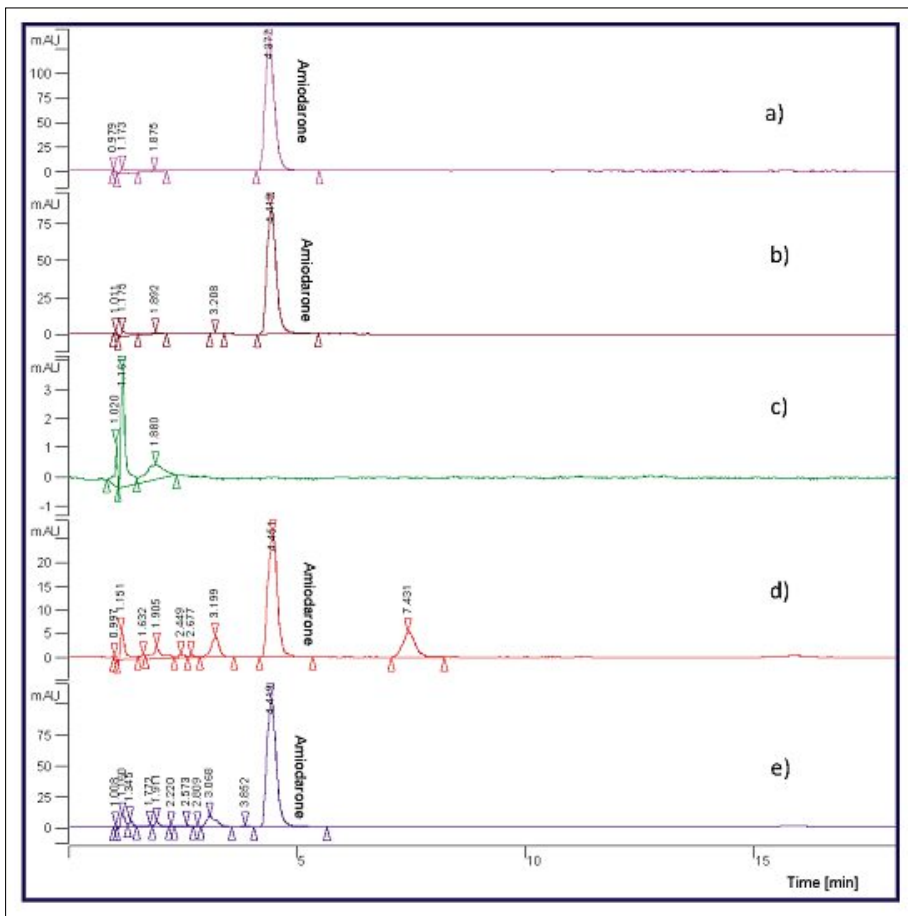

Fig. 2. a) HPLC chromatogram of amiodarone; b) HPLC chromatogram of acidic degradation of amiodarone; c) HPLC chromatogram of basic degradation of amiodarone; d) HPLC chromatogram of heat degradation of amiodarone; e) HPLC chromatogram of UV degradation of amiodarone. 
was validated by the SIPHAROM group (working group of physicians, nurses, and pharmacists from intensive care units of the French-speaking part of Switzerland), which indicates that all intensive care units now use this concentration. Thus, the study demonstrated six-month stability at $5{ }^{\circ} \mathrm{C}$, thereby allowing the production of batches of A-IV solutions. It can be mentioned that if the stability of amiodarone proves to be long enough, the CHUV pharmacy will be able to supply other hospital pharmacies.

Received: February 19, 2012

[1] Institute of Medicine, 'To err is human. Building a safer health system', National Academy Press, Washington DC, 1999.

[2] J. D. Hecq, Ann. Pharm. Fr. 2011, 69, 30.

[3] P. Bonnabry, C. Stucki, Le Moniteur Hospitalier 2011, 237, 19

[4] www.uptodate.com accessed 13 september 2011.

[5] P. Hubert, J.-J. Nguyen-Huu, B. Boulanger, E. Chapuzet, P. Chiap, N. Cohen, P.-A. Compagnon, W. Dewe, M. Feinberg, M. Lallier, M. Laurentie, N. Mercier, G. Muzard, C. Nivet, L. Valat, STP Pharma Pratiques 2003, 13, 101.

[6] P. Hubert, J.-J. Nguyen-Huu, B. Boulanger, E. Chapuzet, P. Chiap, N. Cohen, P.-A. Compagnon, W. Dewe, M. Feinberg, M. Lallier, M. Laurentie, N. Mercier, G. Muzard, C. Nivet, L. Valat, J. Pharm. Biomed. Anal. 2004, 36, 579.

[7] P. Hubert, J. J. Nguyen-Huu, B. Boulanger, E. Chapuzet, P. Chiap, N. Cohen, P. A Compagnon, W. Dewé, M. Feinberg, M. Lallier, M. Laurentie, N. Mercier, G. Muzard, C. Nivet, L. Valat, E. Rozet, J. Pharm. Biomed. Anal. 2007, 45, 70 .

[8] P. Hubert, J. J. Nguyen-Huu, B. Boulanger, E. Chapuzet, P. Chiap, N. Cohen, P. A Compagnon, W. Dewé, M. Feinberg, M. Lallier, M. Laurentie, N. Mercier, G. Muzard, C. Nivet, L. Valat, E. Rozet, J. Pharm. Biomed. Anal. 2007, 45, 82 .

[9] E. Rozet, V. Wascotte, N. Lecouturier, V. Préat, W. Dewé, B. Boulanger, P. Hubert, Anal. Chim. Acta 2007, 591, 239.

[10] A. Bouabidi, E. Rozet, M. Fillet, E. Ziemons, E. Chapuzet, B. Mertens, R. Klinkenberg, A. Ceccato, M. Talbi, B. Streel, A. Bouklouze, B Boulanger, P. Hubert, J. Chomatogr. A. 2010 , 1217, 3180.

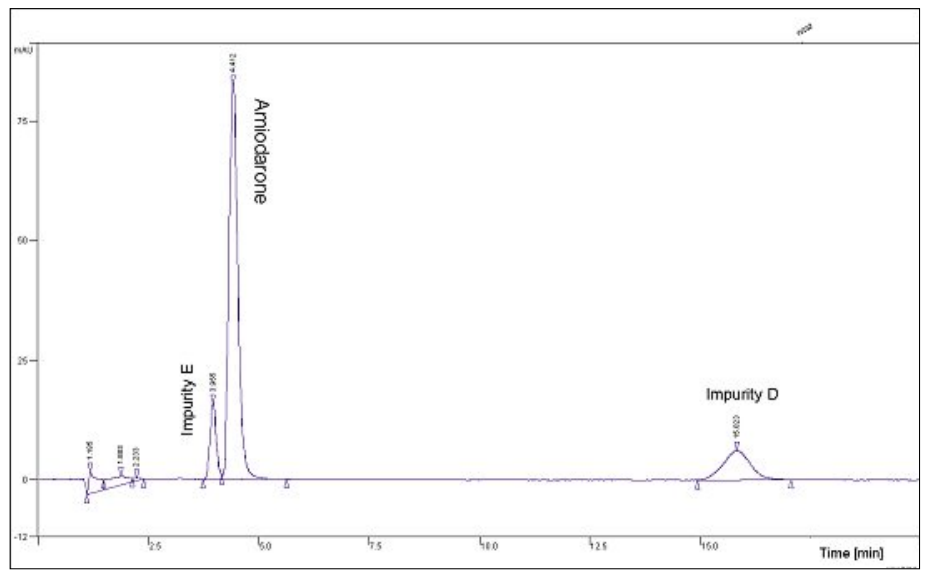

Fig. 3. HPLC chromatogram of amiodarone with impurities $D$ and $\mathrm{E}$.
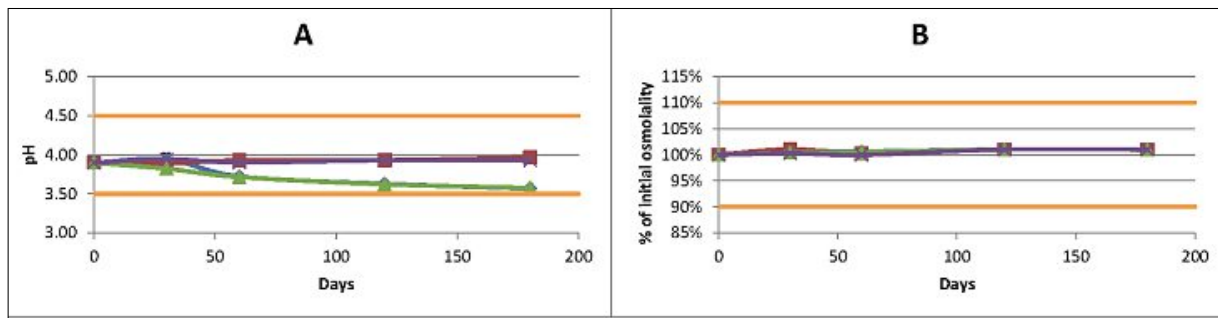

C

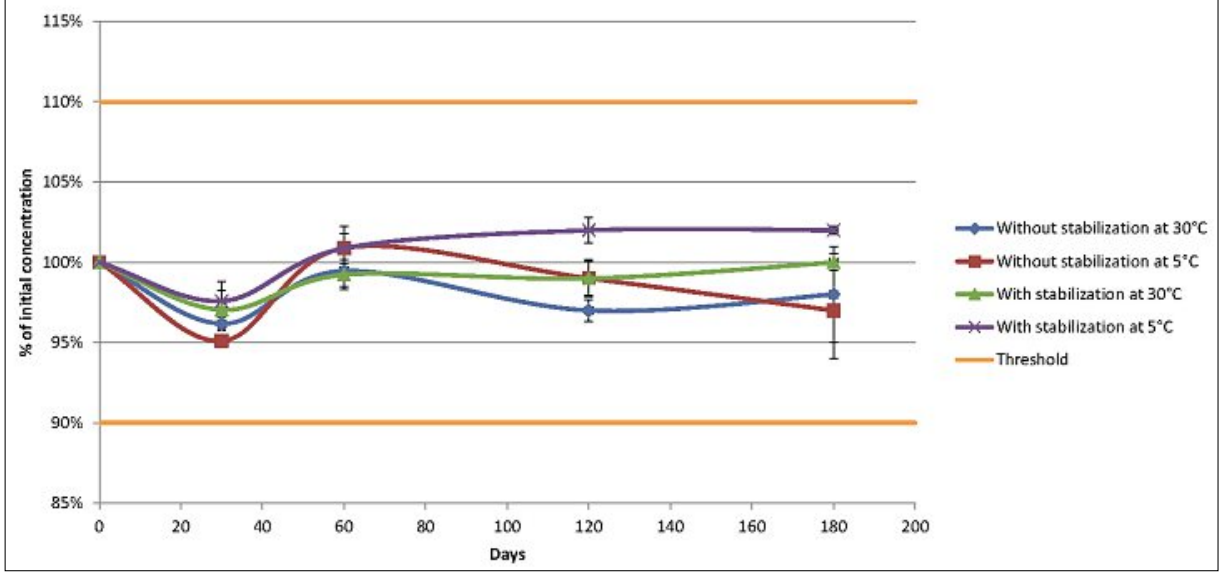

Fig. 4. a) $\mathrm{pH}$ determination of amiodarone $12.5 \mathrm{mg} / \mathrm{mL}$ in glucose $5 \%$ at D0, D30, D60, D120 and D180; b) osmolality determination of amiodarone $12.5 \mathrm{mg} / \mathrm{mL}$ in glucose $5 \%$ at D0, D30, D60, D120 and D180; c) quantification of amiodarone $12.5 \mathrm{mg} / \mathrm{mL}$ in glucose $5 \%$ at D0, D30, D60, D120 and D180 with standard deviations.

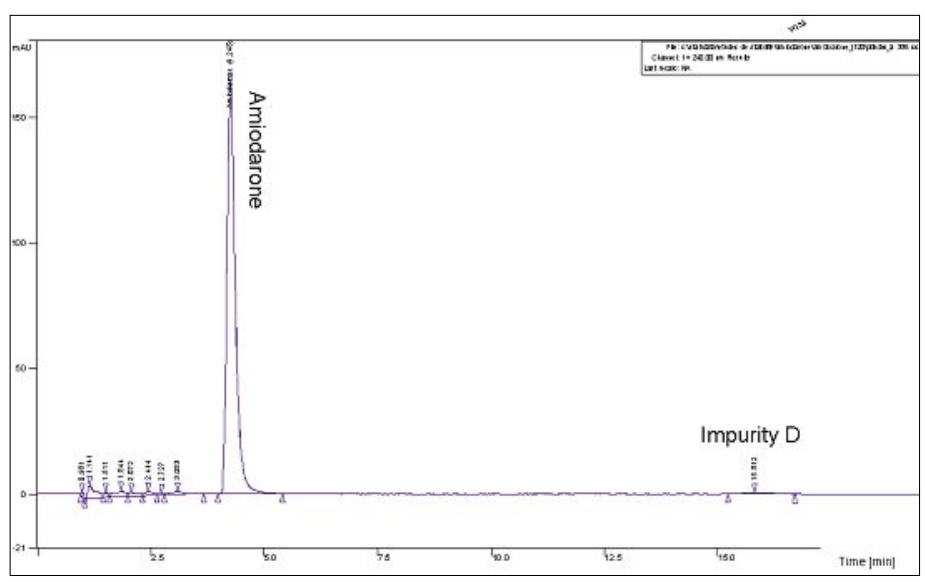

Fig. 5. HPLC chromatogram of A-IV solutions stored at $30^{\circ} \mathrm{C}$ for four months. 